


\title{
Penerapan Gaya Art Deco pada Environmental Graphic Design di SMKN 15 Bandung
}

\author{
Nisa Eka Nastiti,S.Ds.,M.I.Kom. ${ }^{1}$, Novian Denny Nugraha, S.Sn.,M.Sn. ${ }^{2}$, Olivine Alifaprilina S., M.Ds. \\ Desain Komunikasi Visual, Fakultas Kreatif Industri, Universitas Telkom \\ ${ }^{2}$ Desain Komunikasi Visual, Fakultas Kreatif Industri, Universitas Telkom \\ Desain Komunikasi Visual, Fakultas Kreatif Industri, Universitas Telkom \\ *nisaekan@telkomuniversity.ac.id, dennynugraha @telkomuniversity.ac.id, olivinea@ telkomuniversity.ac.id
}

\section{INFO ARTIKEL}

Diterima 09 Juni 2021

Direvisi 09 November 2021

Disetujui 07 Desember 2021

Tersedia Online 04 Februari 2022

\begin{abstract}
ABSTRAK
Proposal pengabdian masyarakat ini merupakan usulan pengajar program studi Desain Komunikasi Visual Fakultas Industri Kreatif Universitas Telkom. Berawal dari potensi SMKN 15 Bandung yang memiliki bangunan bekas zaman kolonial ini cukup tinggi untuk dikembangkan serta pentingnya media informasi. Masalah yang ada yaitu belum tersedianya Environmental Graphic Design pada SMKN 15 Bandung yang informatif, karena masalah tersebut maka penulis bertujuan untuk membuatkan Environmental Graphic Design pada SMKN 15 Bandung dengan gaya art deco. Perancangan ini bertujuan memberi informasi terkait ruang dan lingkungan yang ada di sekitar sekolah serta memberikan branding yang positif pada sekolah.
\end{abstract}

Keyword: environmental graphic design, art deco, informatif

\author{
Korespondensi: \\ Fakultas Industri Kreatif, Universitas Telkom \\ J1. Telekomunikasi No. 1, Terusan Buah Batu, Bandung, 40257) \\ Indonesia. \\ E-mail: nisaekan@telkomuniversity.ac.id
}

ORCID ID:

Penulis Pertama: Nisa Eka Nastiti, S.Ds.,M.I.Kom.

https://doi.org/xxx

Paper_reg_number xxx (C The Authors. Published by Directorate of Research and Community Service, Telkom University.

This is an open access article under the $\mathrm{xxx}$ license (https://creativecommons.org/licenses/xxx) 


\section{Pendahuluan}

SMKN 15 Bandung merupakan salah satu sekolah di Bandung yang lokasinya menempati bangunan bekas zaman Belanda. SMKN 15 memiliki sejarah panjang sebelum akhirnya menjadi sekolah kejuruan, yaitu pertama kali didirikan pada tahun 1919 dengan nama Kweek School Voor Onderwinzer. Beberapa bagian dari bangunan sekolah masih memperlihatkan gaya khas bangunan kolonial. Enviromental graphic design (EGD) sudah tersedia di beberapa titik di sekolah, berupa signage dan wayfinding. Namun, EGD di SMKN 15 Bandung belum didesain dengan maksimal dan kurang memperlihatkan identitas, oleh karena itu tim penulis ingin merancang desain EGD baru untuk SMKN 15 Bandung dengan gaya art deco yang menjadi ciri khas bagunan heritage di Kota Bandung.

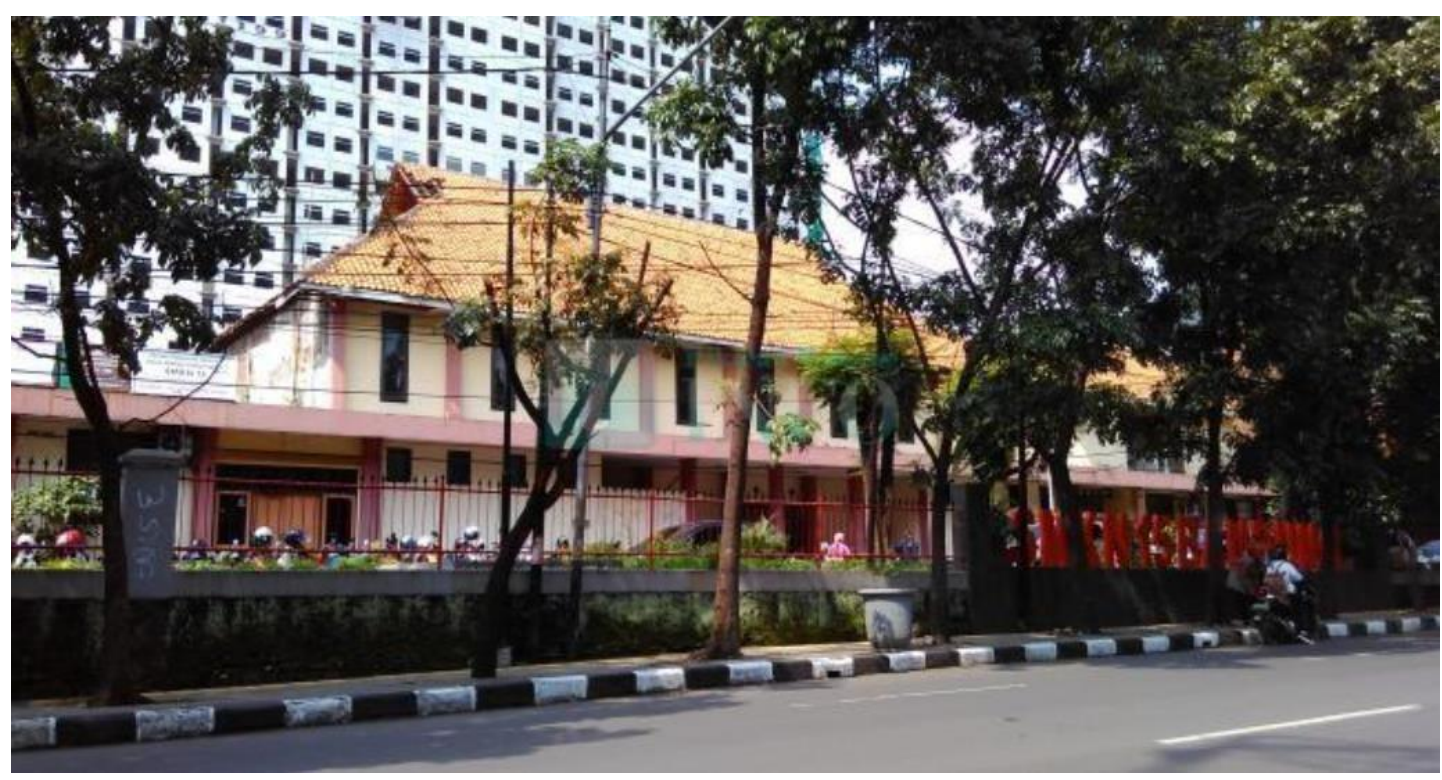

Gambar 1. SMKN 15 Bandung

(Sumber: smkn15bandung.sch.id)

\section{Metode Pelaksanaan}

Kegiatan pelaksanaan abdimas dalam bentuk pembuatan produk yang direncanakan sebagai solusi dari masalah yang ada. Proses pengabdian masyarakat yang dilakukan berawal dari observasi, analisis masalah, pembuatan konsep, perancangan environmental graphic design, setelah perancangan wastafel selesai akan diadakan evaluasi dan dilajutkan dengan pembuatan laporan akhir.

\subsection{Persiapan}

Tahap pertama pengabdian kepada masyarakat ini yaitu tahapan persiapan yang meliputi observasi. Pada tahap observasi ini kegiatan yang dilakukan adalah datang ke SMKN 15 Bandung untuk melihat situasi sekolah. Dari hasil observasi yang didapat, SMKN 15 Bandung EGD di SMKN 15 Bandung belum didesain dengan maksimal dan kurang memperlihatkan identitas, oleh 
karena itu tim penulis ingin merancang desain EGD baru untuk SMKN 15 Bandung dengan gaya art deco yang menjadi ciri khas bagunan heritage di Kota Bandung.

\subsection{Pelaksanaan}

Pelaksanaan kegiatan pengabdian kepada masyarakat ini meliputi analisis masalah, pembuatan konsep dan perancangan environmental graphic design. Pelaksanaanya dimulai dengan sketsa, desain digital sesuai dengan kebutuhan lalu penerapan environmental graphic design di SMKN 15 Bandung.

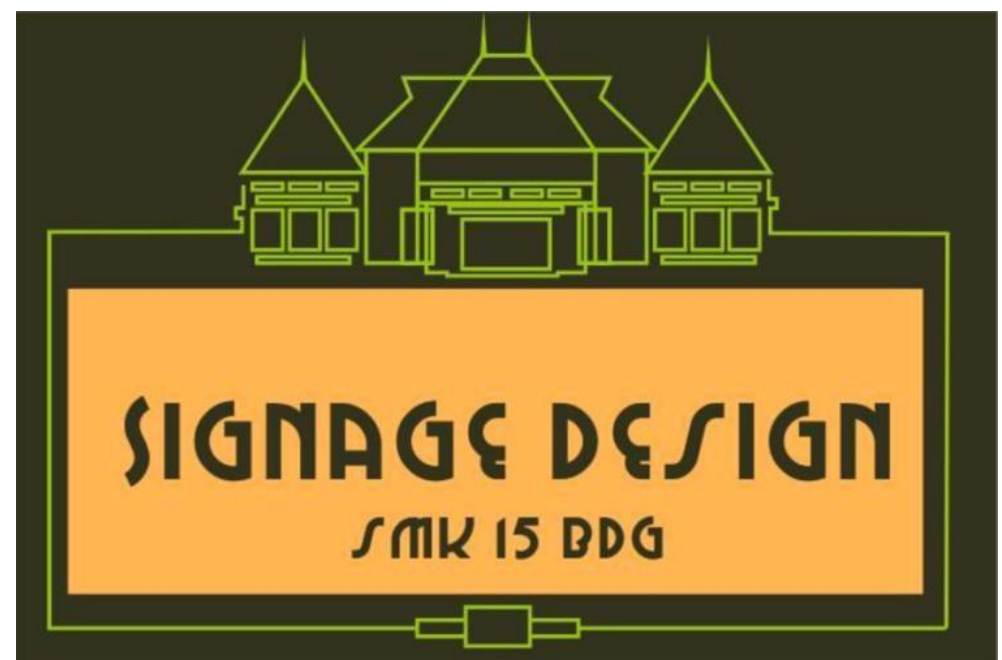

Gambar 2. Desain Digital Signage SMKN 15 Bandung Sumber: Dokumentasi Penulis
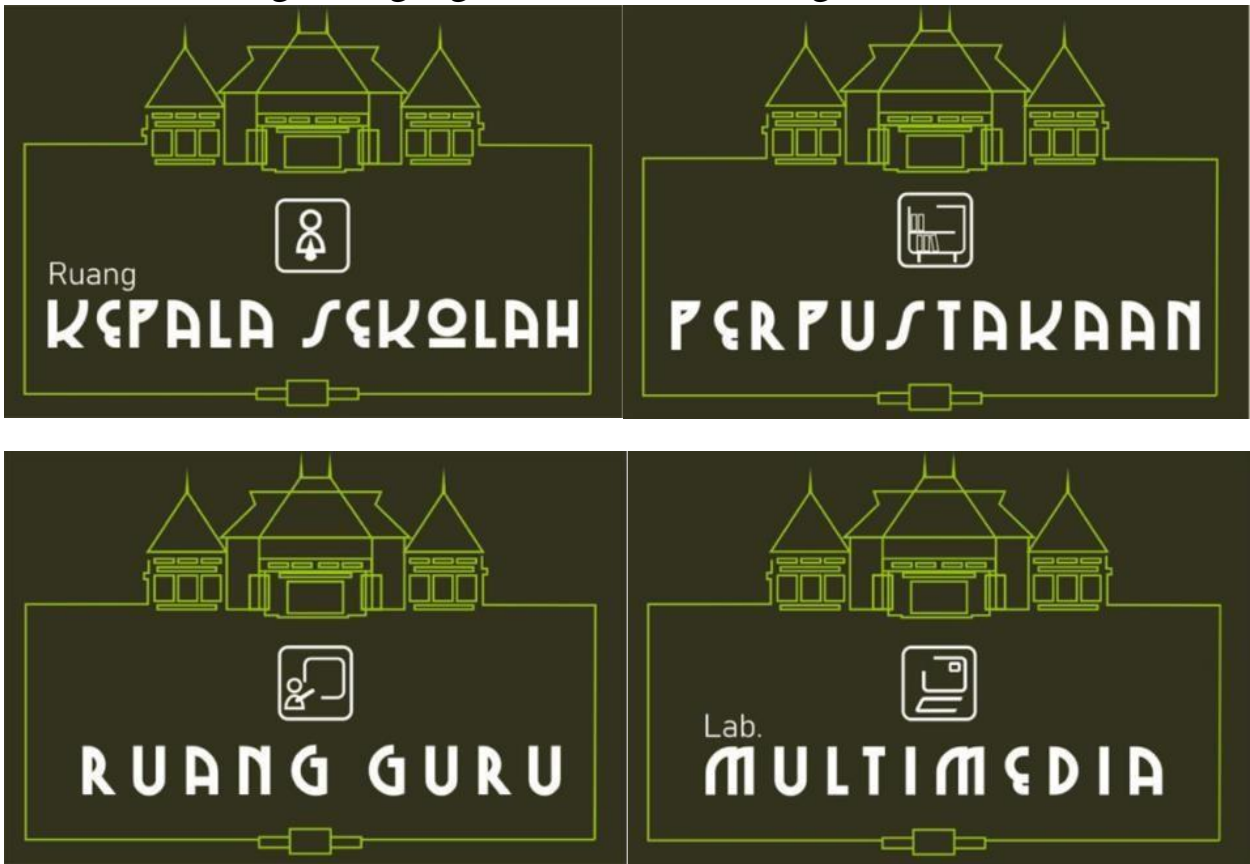

Gambar 3. Desain Digital EGD SMKN 15 Bandung Sumber: Dokumentasi Penulis 


\section{Analisa dan Hasil Kegiatan}

Pelaksanaan kegiatan pengabdian pada masyarakat berupa "Pemberian Desain Environmental Graphic Design pada SMKN 15 Bandung" dilakukan pada:

Hari : Senin

Tanggal: 31 Mei 2021

Lokasi. : SMKN 15 Bandung Jl. Gatot Subroto No.4, Burangrang, Kec. Lengkong, Kota Bandung, Jawa Barat.

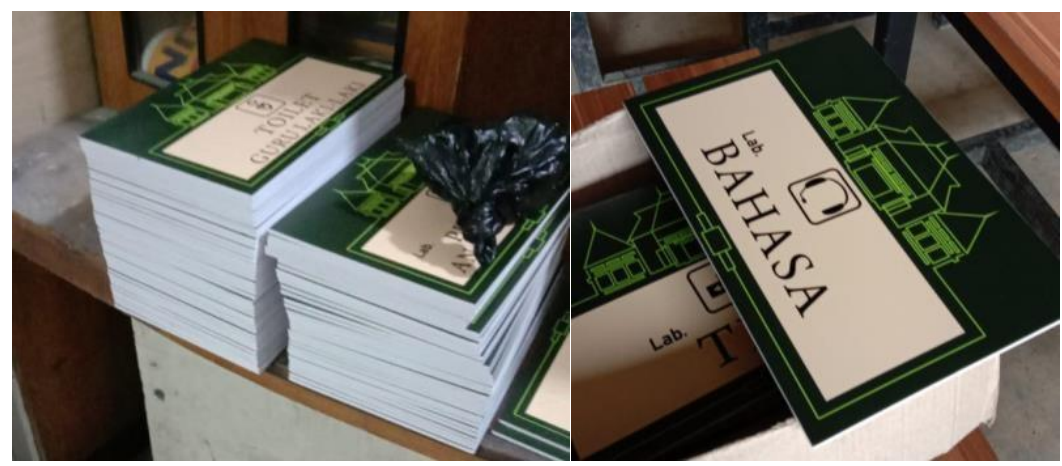

Gambar 4. Hasil EGD SMKN 15 Bandung Sumber: Dokumentasi Penulis

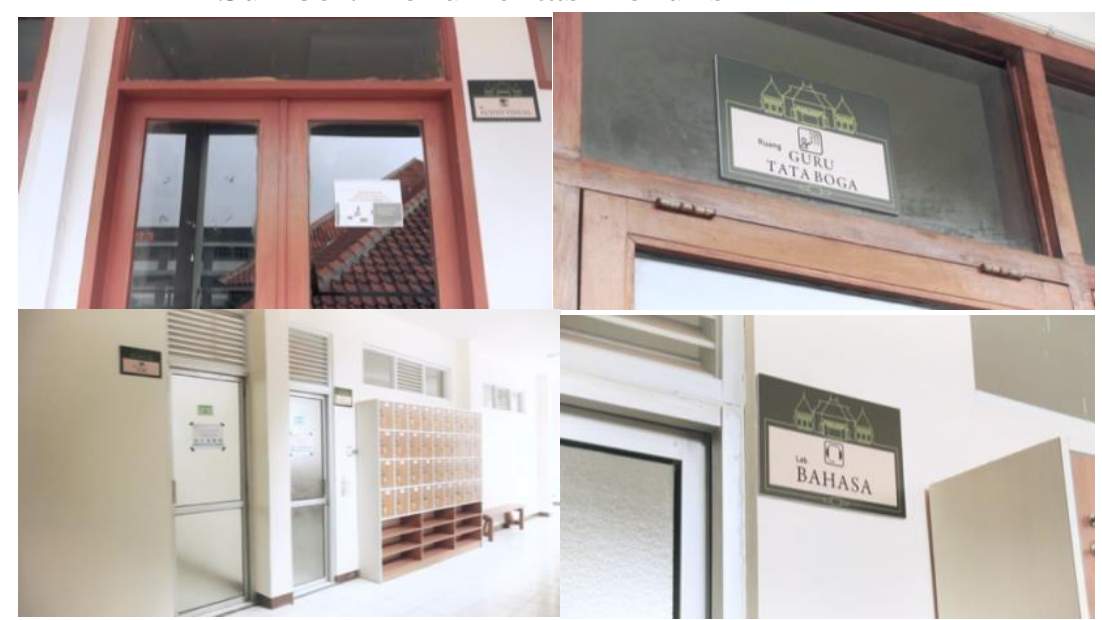

Gambar 5. Pengaplikasian EGD SMKN 15 Bandung Sumber: Dokumentasi Penulis 


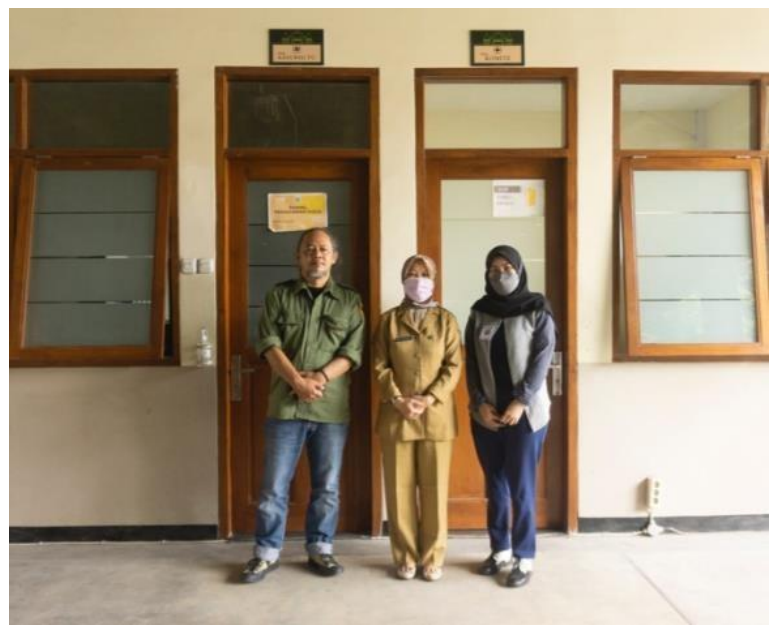

\section{Gambar 6. Foto Bersama Kepala Sekolah SMKN 15 Bandung}

Sumber: Dokumentasi Penulis

Setelah dilakukan penyerahan produk dari tim abdimas Universitas Telkom kepada mitra SMKN 15 Bandung, beberapa staff serta guru yang hadir onsite diberikan kesempatan untuk menjawab survey kepuasan secara lisan. Dari tiga responden, berikut rekap hasil feedback.

\section{Tabel 1. Rekap hasil feedback}

\begin{tabular}{|c|c|c|c|c|c|}
\hline \multicolumn{2}{|c|}{ Aspek Penilaian Terhadap Kegiatan } & \multicolumn{4}{|c|}{ Jumlah Masing-masing Faktor yang Dinilai } \\
\hline 1 & $\begin{array}{l}\text { Program Pengabdian } \\
\text { Masyarakat ini sudah sesuai } \\
\text { dengan tujuan itu sendiri }\end{array}$ & $\begin{array}{c}\text { Sangat tdk } \\
\text { setuju }\end{array}$ & Tdk setuju & Setuju & $\begin{array}{r}\begin{array}{r}\text { Sangat } \\
\text { setuju }\end{array} \\
1\end{array}$ \\
\hline 2 & $\begin{array}{l}\text { Program Pengabdian } \\
\text { Masyarakat ini sudah sesuai } \\
\text { dengan kebutuhan } \\
\text { masyarakat sasarnya }\end{array}$ & & & & 3 \\
\hline 3 & $\begin{array}{l}\text { Waktu pelaksanaan program } \\
\text { Pengabdian } \\
\text { Masyarakat ini relatif telah } \\
\text { mencukupi sesuai kebutuhan }\end{array}$ & & & 2 & 1 \\
\hline 4 & $\begin{array}{l}\text { Dosen Universitas Telkom } \\
\text { bersikap ramah, } \\
\text { cepat dan tanggap membantu } \\
\text { selama kegiatan }\end{array}$ & & & & 3 \\
\hline 5 & $\begin{array}{l}\text { Mitra menerima dan } \\
\text { mengharapkan program } \\
\text { Pengabdian } \\
\text { Masyarakat Universitas Telkom } \\
\text { lanjutan di } \\
\text { masa yang akan datang } \\
\end{array}$ & & & & 3 \\
\hline & Jumlah & & & 4 & 11 \\
\hline & $\begin{array}{r}\% \text { (Jumlah masing-masing : } \\
\text { total) }\end{array}$ & & & $26,6 \%$ & $73,3 \%$ \\
\hline
\end{tabular}


Jumlah setuju + sangat

$99,9 \%$

Berdasarkan tabel hasil rekap, program abdimas yang dilakukan di SMKN 15 Bandung ini dinilai sangat baik, terlihat dari jumlah persen jawaban 'setuju' dan 'sangat' mencapai 99\%.

\section{Kesimpulan dan Saran}

Evaluasi pelaksanaan program adalah membagikan keilmuan yang dimiliki untuk diteruskan kepada masyarakat. Dalam hal ini dipilih berupa pembuatan produk Environmental Graphic Design menggunakan gaya art deco yang bertujuan memberi informasi terkait ruang dan lingkungan yang ada di sekitar sekolah serta memberikan branding yang positif pada sekolah.

Keberlanjutan program setelah kegiatan dilaksanakan dengan pemberian produk yang dapat digunakan oleh mitra dan diprodukais massal. Kami berharap guru, siswa dan seluruh pengurus yang ada disekitar mitra (SMKN 15 Bandung) berpartisipasi untuk memanfaatkan Environmental Graphic Design sebagai media informasi agar lebih bermanfaat dan kemudian dapat berlanjut dengan topik lain dari Desain Komunikasi Visual.

Masukan dan feedback masyarakat terhadap perancangan Environmental Graphic Design yang sudah dilakukan dapat dilihat dari hasil kuesioner dan wawancara. Dari kuesioner tersebut, 99\% responden beranggapan bahwa perancangan Environmental Graphic Design sesuai dengan kebutuhan masyarakat sasar. Responded juga memberi tanggapan positif terhadap perancangan Environmental Graphic Design yang sudah dilakukan oleh dosen dan mahasiswa Telkom University.

\section{DAFTAR PUSTAKA}

[1] Arwas, V., \& Russel, F. (1992). Art deco. Academy Editions.

[2] Calori, C., \& Vanden-Eynden, D. (2015). Signage and wayfinding design: a complete guide to creating environmental graphic design systems. John Wiley \& Sons.

[3] Nastiti, N. E. (2015). Perancangan Sistem Tanda Pada Museum Lampung Di Bandar Lampung. Universitas Telkom.

[4] O'Neill, M. J. (1991). Effects of signage and floor plan configuration on wayfinding accuracy. Environment and Behavior, 23(5), 553-574. [5] PLAN, E., \& DOCU, N. (2014). A GUIDE TO GOOD SHOPFRONT DESIGN AND SIGNAGE.

[6] smkn15bandung.sch.id Diakses pada 8 Februari 2021

[7] Yang, Y., \& Zhu, D. (2020). Environmental Design vs. Environmental Art Design: A Chinese Perspective. Journal of History Culture and Art Research, 9(4), 122-133. 